Ada, G. L., Perry, B. T. \& Abbot, A. (1958). J. gen. Microbiol. 19, 23-39

\title{
Biological and Physical Properties of the Ryan Strain of Filamentous Influenza Virus
}

\author{
By G. L. ADA, BEVERLEY T. PERRY AND A. ABBOT \\ The Walter and Eliza Hall Institute of Medical Research, Melbourne, \\ Victoria, Australia
}

SUMMARY : An influenza A strain, Ryan, isolated in Melbourne in 1954 contains on a particle basis about $20 \%$ filaments. By using the electron microscope for particle counting, the efficiency as haemagglutinin of Ryan 'long' filaments (particles in which length : width $\geqslant 6$ ) was estimated to be about 6 times greater than that of spheres of PR 8 virus. Allantoic fluid preparations of Ryan virus have high values for the ratio (log) EID 50: AD and estimates indicate that a maximum of 6 'long' filaments are equivalent to one EID 50, compared with 18 particles in the case of PR8 virus or 14 particles in the case of a mutant strain of Ryan virus which exists almost exclusively as spheres. Compared with virus PR 8 spheres (16 particles: AD), spherical particles present in filamentous Ryan preparations have a low efficiency as haemagglutinin (29 to 38 particles:AD). These particles are formed before the 'long' filaments, and in fluids harvested $21 \mathrm{hr}$. after inoculation when the proportion of 'long' filaments is very low, about 9 spherical particles constitute 1 EID 50. For the purpose of subsequent chemical examinations filaments were isolated and concentrated by a process involving specific adsorption to and elution from red cells, followed by 3 cycles of differential centrifugation. The ratio of filaments: spheres in such preparations is about 50:50. 'Purified' filaments weigh about 30 times as much as the spherical particles present and account for over $95 \%$ of the total weight present in purified preparations.

It is well known that recently isolated influenza A strains contain a high proportion of filamentous forms. These filaments have been shown to possess many of the biological properties characteristic of spherical influenza virus particles, such as serological, haemagglutinating and enzymic behaviour (Chu, Dawson \& Elford, 1949; Bang \& Isaacs, 1957; Burnet \& Lind, 1957), but the question of the infectivity of filaments relative to that of spherical particles has remained in doubt. Morgan, Rose \& Moore (1956) found in electron micrographs of sections of chorioallantois infected with the filamentous strain A/Persian Gulf/2/52 that while spherical particles possessed an electron opaque core, filaments appeared as empty shells. Their interpretation of this finding was that the spherical form of the virus was the elementary infectious unit and that the filamentous form was largely or completely non-infectious. Using quantitative counting techniques, Donald \& Isaacs (1954b) calculated that about 10 filaments of the A/Persian Gulf/2/52 strain were needed to induce infection. This compared with a figure of 10 for the spheres from a good preparation of a non-filamentous strain. It is now evident that filaments readily break down during manipulation (Valentine \& Isaacs, 1957; Burnet \& Lind, 1957), and this indicates that the actual counts of Donald \& Isaacs were overestimates of the number of filaments originally present. Hence it appears that 
less than 10 filaments of this strain are necessary to induce infection (Valentine \& Isaacs, 1957).

It was desirable to have some information about the chemical composition of filaments, particularly for comparison with the properties of spherical particles. The A strain Ryan (Ryan F.), which was isolated during the 1954 epidemic in Melbourne, was studied because of the development (by passage at low dilution) of a mutant strain (Ryan Sph.) which exists almost exclusively as spheres (Burnet \& Lind, 1957). The latter seemed an ideal control in both biological and chemical work for the spherical particles present in preparations of Ryan F. virus. Furthermore, preparations of Ryan F. virus had values for the ratio 50\% egg infectivity dose : agglutinating dose (EID 50:AD) which were as high as those given by Ryan Sph. or PR 8 viruses. Preparations of the other well studied filamentous strain, A/Persian Gulf/2/52 (Persia F.), have given lower values for this ratio (Donald \& Isaacs, 1954b).

The value of the ratio filaments : spheres in Ryan F. is $1: 4$ so that before chemical studies it was necessary to isolate and concentrate the filamentous particles. To put the chemical results on a quantitative basis, counting techniques were used to determine the number of particles/mg. dry weight in purified preparations. This led to the findings: (1) that the 'spherical particles' present in preparations of both crude and purified Ryan F. virus are less efficient as haemagglutinin than the spheres present in preparations of PR 8 or Ryan Sph. viruses; (2) that fewer Ryan filaments than PR 8 or Ryan spheres are necessary to induce infection in the embryonated egg. Details of these findings are presented in this paper; the results of nucleic acid analyses of Ryan flaments are given in the following paper.

\section{METHODS}

Strains of influenza virus. The following virus strains were used:

PR 8 (classical influenza A virus strain, isolated by Francis in 1934).

Lee (classical influenza B virus strain, isolated by Francis in 1940).

Ryan (influenza A prime virus strain isolated during an epidemic in Melbourne in 1954). Two different lines of Ryan virus were used: one highly filamentous (Ryan F.), as was the virus on initial isolation; the other consisted mainly of spheres. This spherical form of Ryan virus (Ryan Sph.) gradually emerged during continued passage of the virus at low dilution, and it appears to differ from the parent Ryan only in having a much lower proportion of filaments (Burnet \& Lind, 1957). The inoculum for batches of Ryan Sph. virus was a limit dilution fluid obtained after 16 successive passages at a $10^{-2}$ dilution, and that for Ryan F. virus was a fluid from either the fifth or sixth limit dilution passage.

A/Persian Gulf/2/52 (Persia F.). Received from Dr A. Isaacs, and passaged three times in the allantoic cavity.

Groroth of viruses. The inocula for PR 8 and Lee viruses were limit dilution fluids which had been kept at $c .-70^{\circ}$. A fresh ampoule was thawed for each inoculation, the fluid diluted to $10^{-6}$ in $10 \%$ horse-serum saline containing 
antibiotics, and inoculated into the allantoic cavity of 200-300 11-day fertile hen eggs. After $\mathbf{2}$ days incubation at $\mathbf{3 5}^{\circ}$ the fluids of each batch were harvested and pooled, and immediately titrated for haemagglutinin and for infectivity in eggs.

The fluids used for the inocula of both forms of Ryan virus and for Persia F. virus were stored in glycerol at $-10^{\circ}$. Batches of 100-200 10- or 11-day fertile hen eggs were inoculated into the allantoic cavity with a dilution of the inoculum varying from $10^{-2}$ to $10^{-4}$, and the fluids harvested and pooled after 3 days incubation at $35^{\circ}$. Incubation was extended to 3 days to allow the development of long filaments (Donald \& O'Dea, unpublished; quoted by Burnet \& Lind, 1957). Titrations for haemagglutinin and for egg infectivity were carried out with the freshly-harvested fluid.

Preparation of Ryan antiserum. Antiserum was prepared in a rabbit against the filamentous Ryan virus. The rabbit was given two intravenous inoculations of $1 \mathrm{ml}$. each of concentrated virus, with an interval of 2 weeks between inoculations. The serum used was taken 4 weeks after the first inoculation. One part of serum was treated with two parts of crude receptor-destroying enzyme (Burnet, McCrea \& Stone, 1946) for $1 \mathrm{hr}$. at $37^{\circ}$ in order to destroy any non-specific inhibitor of haemagglutination. To ensure the specificity of the serum for Ryan virus, purified LEE virus $\left(1 \times 10^{5}\right.$ agglutinating doses/ 2.5 ml. undiluted serum) was added and the mixture kept at $4^{\circ}$ for $1 \mathrm{hr}$. Free and combined Lee virus was removed by centrifugation $(35,000 \mathrm{~g}, 30 \mathrm{~min}$.), sodium citrate was added to the supernatant serum to give a final concentration of $2 \%(\mathrm{w} / \mathrm{v})$ and the serum was heated for $30 \mathrm{~min}$. at $65^{\circ}$ to destroy the receptor-destroying enzyme. This method of preparing a strain-specific antiserum is a modification of the procedure originally used by Hirst (1952).

Physiological saline. $0 \cdot 85 \mathrm{~g}$. NaCl$/ 100 \mathrm{ml}$. distilled water.

Phosphate buffered saline (pH 6.7). See Donald \& Isaacs (1954a).

Bicarbonate saline. Physiological saline containing $5 \mathrm{mg}$. sodium bicarbonate/ $100 \mathrm{ml}$. saline; $\mathrm{pH}$ value $c .7 \cdot 5$.

Haemagglutinin titration. Serial twofold dilutions of virus were prepared in $0.25 \mathrm{ml}$. volumes in physiological saline, and to each dilution was added $0.25 \mathrm{ml}$. of a $1 \%$ suspension of fowl red blood cells. The cells were allowed to settle at room temperature, and the end-point read as the usual degree of partial agglutination. The reciprocal of the end-point dilution of the virus is the haemagglutinin (HA) titre, i.e. one agglutinating dose (1 AD). Most results given in the experimental section are the average of duplicate titrations.

Infectivity titrations. Serial tenfold dilutions of virus fluids were prepared in $10 \%$ horse-serum saline containing penicillin and streptomycin, and $0.05 \mathrm{ml}$. of each dilution was inoculated into the allantoic cavity of each of ten 11-day fertile hen eggs. After 3 days incubation at $35^{\circ}$ the eggs were tested for the presence or absence of haemagglutinin in the allantoic fluids. The titre (EID 50) is expressed as the index of the reciprocal of the dilution yielding $50 \%$ positive fluids.

EID 50:AD ratio. Each virus fluid is characterized by its $\left(\log _{10}\right)$. 
EID 50:AD ratio, i.e. (log) 50\% egg infectivity dose/ml. : (log) agglutinating dose/ml.

Centrifugation. Centrifugation was carried out in two types of centrifuges: (a) fitted with swinging buckets, mean radius $=10 \mathrm{~cm}$.; (b) a Spinco model L, fitted with a no. 30 rotor, mean radius $=7 \cdot 8 \mathrm{~cm}$., angle of tube from the vertical axis $=26^{\circ}$.

Electron microscopy. A Siemen's microscope, type UM 100, was used with an accelerating voltage of $60 \mathrm{kV}$. and a $50 \mu$ objective aperture. Pictures were taken at a final screen magnification of about 6000. All specimens to be examined were adsorbed to the stromata of fowl red blood cells prepared according to Donald \& Isaacs (1954a) except that it was found unnecessary to treat the stromata with periodate. In early experiments involving large batches of allantoic fluid, samples were taken for the purpose of obtaining approximate figures for the relative proportions of filaments to spheres. The virus was adsorbed to stromata, the coated stromata placed on grids and shadowed with gold manganin. Later when it became necessary to know the actual number of particles/agglutinating dose (AD) for different preparations of virus, the following procedure was adopted. 400-800 AD of virus contained in $1 \mathrm{ml}$. fluid were added to $1 \mathrm{ml}$. of a suspension containing about $1 \times 10^{8}$ stromata $/ \mathrm{ml}$. After standing at $4^{\circ}$ for 1-2 hr., the stromata were sedimented by light centrifugation, resuspended in phosphate buffered saline and fixed with $0 \cdot 1 \%(\mathrm{w} / \mathrm{v})$ osmic acid. Titration of the supernatant fluid indicated that at least $90 \%$ of the virus had adsorbed to the stromata. After a minimum of 30 min. fixing, the stromata were washed several times with distilled water and mounted from very dilute suspensions on collodion-coated grids. After shadowing with gold manganin, the number of virus particles/stroma was determined by counting particles casting a shadow, doubling this figure to allow for particles on the underside of the membrane and allowing for particles overlaying the nucleus, as described by Donald \& Isaacs (1954a). The values thus obtained for PR 8 virus were about double the figures quoted by Donald $\&$ Isaacs $(1954 a)$. With preparations of filaments it was sometimes noticed that where a filament extended beyond the red cell membrane edge, the latter gave the impression of overlaying the filament. In such cases, the unadsorbed portion of the filament was narrower and appeared to throw a longer shadow than the adsorbed portion. It appeared that either the stroma is so thin that it closely follows the contours of the virus particle or that the latter may in some cases protrude through the membrane. Owing to the wide variation in size of influenza virus particles, it was not possible to decide by the length of the shadow cast whether a particle was above or below the membrane. This was confirmed in later experiments when it was found that micrographs of a viruscoated stroma, taken before and after shadowing, showed the same number and distribution of particles (see also Tyrrell \& Valentine, 1957). Subsequently, all counts were made on micrographs obtained by direct transmission. The area of stroma counted relative to the area of the whole stroma was estimated planimetrically and a further $5 \%$ added to allow for the mound effect over the nucleus. The values quoted in Tables 1,2 and 6 were obtained with this 
technique. Plate 1, fig. 1, is an unshadowed micrograph of Ryan Sph. virus.

However, the two techniques were found to give different results when counting particles from filamentous virus preparations. Structures which were counted as rods in shadowed micrographs often appeared to be linear aggregates of spherical particles in unshadowed micrographs and were counted as spherical particles in the work reported in this paper. This, in part, accounts for the discrepancy between earlier estimates of the proportion of filaments (30\%) as compared with the value of $20 \%$ (Table 4 ) obtained later when counts were made using unshadowed micrographs. We cannot explain the discrepancy between our estimate of about $30 \%$ for the proportion of filaments in Persia F. virus and the value of $45 \%$ quoted by Donald $\&$ Isaacs $(1954 b)$.

Statistical calculations. These were carried out according to Fisher (1954).

\section{RESULTS}

Definition of a filament. In conformity with the practice of other workers, particles having a value greater than 2 for the ratio length:diameter, are classified as filaments. It has been necessary, however, to subdivide this fraction into short and long filaments as neither preparations of filaments free from spherical particles, nor preparations of spherical particles free from short filaments, have been obtained. Supernatant fluids from centrifugation of Ryan F. fluids contain some filaments, the maximum size of the particles being about $\mathrm{L}: D=5$. In this paper, these and shorter rods are designated as short filaments; particles of size $L: D \geqslant 6$ are designated long filaments. Unless otherwise mentioned, the properties found will refer mainly to long filaments.

\section{Properties of virus in infected allantoic fluid}

Examination in the electron microscope. Plate 1, fig. 1, is an electron micrograph of an allantoic fluid preparation of Ryan Sph. virus. There is a complete absence of long filaments and a small number only of short filaments (proportion $=4 \%$; see Table 1 ). The picture is not unlike those given by well adapted influenza A strains.

Plate 1, fig. 2, is an electron micrograph of an allantoic fluid preparation of Ryan F. virus. The average proportion of filaments was found to be $20 \%$ (Table 1; Fig. 2). For the reasons given in Methods, this value is lower than that previously quoted (Ada, Perry \& Edney, 1957). Morphologically, Ryan filaments resembled those present in Persia F. virus. There was a scarcity of 'Archetti bodies' attached to Ryan filaments though occasionally such structures were seen detached from filaments on the red cell membrane. In direct transmission micrographs, long filaments exhibited little sign of continuous internal structure. Some filaments had a short section of greater electron density, often at one end. In some preparations, many filaments appeared to have spheres attached to the surface. In most cases, this proximity was probably accidental, but in others, the spheres seemed to be budding off from the filament. 
Number of virus particles per agglutinating dose. These were estimated as described in Methods. To minimize errors, counts were done on batches of 5-10 specimens at a time, using the same preparations of fowl red cells for haemagglutinin titrations and of stromata for each specimen in a batch. Generally, PR 8 virus was used as a control in all batches; in the limited number of experiments carried out, the variation between different PR 8 preparations estimated on the same day was less than the variation in values given by one preparation estimated on different days. Counts on Persia F. virus were carried out for purposes of comparison with Ryan F. virus. Values for the ratio, number of particles:AD for spherical particles present in filamentous virus preparations were obtained by using the top 2-3 ml. of $6 \mathrm{ml}$. lots of virus preparations centrifuged at $10,000 \mathrm{~g}$ for $20 \mathrm{~min}$. in the Spinco ultracentrifuge, leaving the brake off to allow slow deceleration. As controls, preparations of PR 8 and Ryan Sph. viruses were treated similarly.

(i) 72-hr. fluids. The result of particle counts on 42-hr. PR 8 fluids and on 72-hr. fluids of Persia F., Ryan F. and Ryan Sph. viruses are presented in Table 1. The values for the ratio, number of particles:AD for PR8 and Ryan Sph. viruses agree well with the figure of $16 \times 10^{6}$ for PR8 virus reported by Donald \& Isaacs (1954a). The findings that the supernatant fluids of both PR 8 and Ryan Sph. have similar values indicate the homogeneity of these virus preparations. The slightly lower value given by Persia F. supernatant fluid $\left(14 \times 10^{6}\right)$ is probably due to the $8 \%$ of short filaments present. Persia F. virus itself has a much lower value $\left(9 \times 10^{6}\right)$. In contrast to this, the figure for Ryan F. virus is similar to that given by PR8 or Ryan Sph. viruses. The value for Ryan F. supernatant fluid is, however, significantly higher than that for Ryan F. virus $(t=6, n=14, P<0.01)$, PR 8 virus $(t=6 \cdot 3, n=18, P<0.01)$ or Ryan Sph. virus $(t=5 \cdot 6, n=10, P<0.01)$.

Table 1. The number of virus particles per agglutinating dose in allantoic fluid preparations of virus

Virus preparations

\begin{tabular}{|c|c|c|c|c|c|c|c|}
\hline PR 8 & $\begin{array}{c}\text { PR 8 } \\
\text { super- } \\
\text { natant* }\end{array}$ & Ryan Sph. & $\begin{array}{c}\text { Ryan Sph. } \\
\text { super- } \\
\text { natant* }\end{array}$ & Persia F. & $\begin{array}{c}\text { Persia F. } \\
\text { super- } \\
\text { natant* }\end{array}$ & Ryan F. & $\begin{array}{c}\text { Ryan F. } \\
\text { super- } \\
\text { natant* }\end{array}$ \\
\hline $18 \pm 4$ & $17 \pm 4$ & $15 \pm \frac{2}{6}$ & $\begin{array}{r}17 \\
1\end{array}$ & $9 \pm \frac{1}{5}$ & $\begin{array}{c}14 \pm 2 \\
3\end{array}$ & $\frac{14 \pm 5}{10}$ & $38 \pm 10$ \\
\hline 11-24 & 14-21 & $13-19$ & & $7-10$ & $12-16$ & $10-22$ & 26-50 \\
\hline$<2$ & $<2$ & $4 \dagger$ & $3 \dagger$ & 27 & $8 \dagger$ & 20 & $\mathbf{5 \dagger}$ \\
\hline
\end{tabular}

* Supernatant refers to the top $3 \mathrm{ml}$. of $6 \mathrm{ml}$. lots of virus preparations after centrifugation at $10,000 \mathrm{~g}$ for 20 min.

$\dagger$ Almost entirely short filaments (see text).

$\ddagger$ S.D. $=\sqrt{\frac{\Sigma(x-\bar{x})^{2}}{n-1} \text {. }}$

The efficiency as haemagglutinin of Ryan long filaments may be estimated from the data in Table 1 by assuming that both Ryan F. and Ryan F. supernatant fluids contain about $5 \%$ short filaments so that the essential difference 
between the two preparations is that Ryan F. virus contains $15 \%$ long filaments. On this basis, we have

$$
\begin{aligned}
& \text { In Ryan F. virus } 2 \times 10^{6} \text { filaments }+12 \times 10^{6} \text { spheres } \equiv 1 \text { A.D. } \\
& \text { In Ryan F. supernatant fluid } \quad 38 \times 10^{6} \text { spheres } \equiv 1 \text { A.D. }
\end{aligned}
$$

from which it is readily calculated that about $3 \times 10^{6}$ long filaments are equivalent to 1 A.D. A similar figure is also given by the filaments in Persia F. virus. If we take $18 \times 10^{6}$ as the number of spheres in a non-filamentous strain which is equivalent to 1 A.D., Ryan filaments in an allantoic fluid preparation are about six times more efficient as haemagglutinin than are such spheres. This compares with a figure of seven or eight calculated previously for Persia filaments (Isaacs, 1957; Ada et al. 1957).

(ii) 21- and 30-hr. fluids. There are several possible explanations for the finding that the spherical particles present in Ryan F. preparations were less efficient as haemagglutinin than were the spheres in PR 8 or Ryan Sph. preparations. One possibility which could be tested experimentally was that such a preparation is a mixture of 'normal' spheres + spherical particles which arise by breakdown of the long filaments. It was originally found by Drs Donald and O'Dea (quoted by Burnet \& Lind, 1957), that after inoculation with Ryan F. virus the early yields of virus showed a very low ratio of filaments to spheres. In later harvests, this ratio increased and the filaments found became progressively longer. If the above hypothesis is correct, early fluids would mainly contain spherical particles of the usual efficiency as haemagglutinin. Eggs were therefore inoculated in the usual way and harvested at 21-23 hr. when the pools of allantoic fluids were found to have a low titre of haemagglutinin (titre at $18 \mathrm{hr}$. <2; mean titre at $21 \mathrm{hr} .=25$ ). As a control, eggs were inoculated with Ryan Sph. virus, but these were harvested at $30 \mathrm{hr}$., as fluids harvested at 21-23 hr. had haemagglutinin titres of less than 2. The results are shown in Table 2.

Table 2. The number of spherical virus particles per agglutinating dose of

\begin{tabular}{|c|c|c|c|c|c|}
\hline $\begin{array}{c}\text { Virus } \\
\text { preparation }\end{array}$ & $\begin{array}{c}\text { Time of } \\
\text { harvesting after } \\
\text { inoculation } \\
\text { (hr.) }\end{array}$ & $\begin{array}{l}\text { Mean value } \\
\text { and s.D. } \\
\left(\times 10^{-6}\right)\end{array}$ & $\begin{array}{c}\text { No. of } \\
\text { experiments }\end{array}$ & $\begin{array}{c}\text { Range } \\
\left(\times 10^{-6}\right)\end{array}$ & $\stackrel{\%}{\text { Filaments } \dagger}$ \\
\hline Ryan F. & $21-23$ & $29 \pm 5$ & 5 & 22-34 & 6 \\
\hline $\begin{array}{l}\text { Ryan F. } \\
\text { supernatant }\end{array}$ & $72^{*}$ & $38 \pm 10$ & 6 & $26-50$ & 5 \\
\hline Ryan Sph. & $\begin{array}{l}30 \\
72^{*}\end{array}$ & $\begin{array}{l}13 \\
15 \pm 2\end{array}$ & $\begin{array}{l}2 \\
6\end{array}$ & $13-19$ & $\begin{array}{l}3 \\
4\end{array}$ \\
\hline
\end{tabular}
Ryan virus harvested at different times after inoculation

Thirty-hr. Ryan Sph. preparations have values within the range found previously for $72 \mathrm{hr}$. samples. In confirmation of the finding of Donald and O'Dea, early harvests of eggs inoculated with Ryan F. virus contain a low 
proportion of long filaments. The value of the ratio, number of particles:AD for the spheres present in such preparations is lower than, but not significantly different $(t=1 \cdot 8, n=9, P=0 \cdot 1)$ from the value of the spheres present in $72 \mathrm{hr}$. Ryan $F$. preparations, but it is significantly different from the value for the spheres present in Ryan Sph. virus $(t=5 \cdot 2, n=9, P<0 \cdot 01)$ or in PR 8 virus $(t=4.6, n=17, P<0.01)$. Thus, spheres of low efficiency as haemagglutinin occur before the formation of long filaments. Their possible mode of formation will be discussed later. In several experiments, samples of Ryan F. harvested at $30 \mathrm{hr}$. were found to have an average haemagglutinin titre of 170 and to contain about $9 \%$ of filaments.

Infectivity of Ryan virus particles. In contrast to the published figures for Persia F. virus (Donald \& Isaacs, 1954 $b$ ), high values for the ratio EID 50:AD characterize preparations of Ryan F. virus; it was partly for this reason that it was chosen as a suitable strain for study. In a preliminary series of experiments, a mean value of 6.0 was obtained which compares with values of 6.0 and 6.1 given by PR 8 and Ryan Sph. viruses respectively (Table 3).

Table 3. Infectivity to agglutinating dose ratios (log EID50:AD) for $P R 8$ and Ryan viruses

Virus preparations

\begin{tabular}{|c|c|c|c|c|}
\hline & PR8 & Ryan Sph. & $\begin{array}{c}\text { Ryan filaments } \\
(21 \text { hr.) }\end{array}$ & $\begin{array}{l}\text { Ryan filaments } \\
(\mathbf{7 2} \mathrm{hr} .)\end{array}$ \\
\hline $\begin{array}{l}\text { Mean value and } \\
\text { S.D. }\end{array}$ & $6 \cdot 0 \pm 0 \cdot 3$ & $6 \cdot 2,6 \cdot 2,5 \cdot 9$ & $6 \cdot 5 \pm 0 \cdot 3$ & $6.0 \pm 0.5$ \\
\hline $\begin{array}{l}\text { Number of } \\
\text { experiments }\end{array}$ & 12 & $\mathbf{3}$ & 6 & 9 \\
\hline Range of values & $6 \cdot 5-4 \cdot 8$ & - & $6 \cdot 1-6 \cdot 9$ & $6.9-4.8$ \\
\hline
\end{tabular}

The relative infectivity of Ryan filaments could be calculated from these figures provided the infectivity of the spherical particles present in such preparations is known. It was previously assumed (Ada et al. 1957) that spheres present in the non-filamentary strains, PR 8 and Ryan Sph. would be the best control for this purpose. It is now known that at least with respect to their efficiency as haemagglutinin, the spherical particles in Ryan F. preparations differ from those in PR 8 and Ryan Sph. viruses. Consequently infectivity determinations were carried out on a number of $\mathbf{7 2} \mathrm{hr}$. Ryan $\mathbf{F}$. fluids and on the supernatant fluids derived from them by centrifugation (see previous section). The titrations were carried out on both samples in each experiment using a common pool of eggs. Nine of the ten determinations are reported in Table 4; the tenth determination was discarded for technical reasons.

The difference of $0 \cdot 21 \mathrm{log}$. units between the two mean values is significant and their values can now be used to determine the infectivity of the Ryan long filaments as follows: number of particles/AD for Ryan $\mathrm{F}$. virus $=14 \times 10^{6}$, for Ryan F. supernatant fluid $=38 \times 10^{6}$ (Table 1). EID 50:AD for Ryan F. virus $=0 \cdot 6 \times 10^{6}$ for Ryan F. supernatant fluid $=1 \times 10^{6}$ (Table 4). 
Table 4. Infectivity to agglutinating dose ratios (log: $E I D 50: A D)$ of preparations of Ryan filaments and of the spherical particles present in such preparations.

\begin{tabular}{|c|c|c|c|c|c|}
\hline $\begin{array}{l}\text { Virus } \\
\text { preparations }\end{array}$ & Experimental values & Mean* & $\bar{x}-x^{\prime *}$ & $t^{*}$ & $p^{*}$ \\
\hline $\begin{array}{l}72 \mathrm{hr} \text {. Ryan F. } \\
72 \mathrm{hr} \text {. Ryan F. } \\
\text { supernatant }\end{array}$ & $\begin{array}{l}5 \cdot 0,5 \cdot 7,6 \cdot 4,5 \cdot 3,4 \cdot 9,6 \cdot 8,5 \cdot 8,6 \cdot 2,6 \cdot 0 \\
5 \cdot 1,6 \cdot 2,6 \cdot 8,5 \cdot 6,5 \cdot 3,6 \cdot 4,6 \cdot 0,6 \cdot 3,6 \cdot 3\end{array}$ & $\begin{array}{r}5 \cdot 79 \\
6 \cdot 0\end{array}$ & \} 0.21 & $2 \cdot 4$ & 0.05 \\
\hline
\end{tabular}

Therefore, the number of particles: EID 50 for Ryan F. virus $=\mathbf{2 3}$ and for Ryan F. supernatant fluid $=\mathbf{3 8}$.

Of this figure 23 for Ryan F. virus, $85 \%$ or approximately 20 particles were spheres and contributed $20 / 38$ or 0.5 EID 50. Three long filaments will then contribute 0.5 EID 50 or 6 long filaments will be equivalent to 1 EID 50. This compares with 18 PR 8 particles or 14 Ryan spheres. It is interesting to note that the spherical particles present in $21 \mathrm{hr}$. Ryan F. fluid have a (log) EID 50:AD ratio of 6.5 (Table 3). Despite the fact that $29 \times 10^{6}$ of these particles constitute $1 \mathrm{AD}$, it may be calculated (as above) that about 9 particles are equivalent to 1 EID 50. The lower infectivity of the spherical particles in $72 \mathrm{hr}$. fluids is discussed later.

\section{Properties of purified virus.}

Purification of virus. Lee, PR8 and Ryan Sph. viruses were purified according to the procedure described previously (Ada \& Perry, 1954, 1956). This involved specific adsorption to and elution from human red cells followed by two cycles of differential centrifugation (virus sedimentation; $38,000 \mathrm{~g}$, $30 \mathrm{~min}$; clarification of resuspended virus, $7000 \mathrm{~g}, 10 \mathrm{~min}$ ).

In early experiments, in which Dr H. B. Donald took part, several methods designed to separate the filaments from spherical particles in Ryan F. virus were tried. These involved filtration through different materials and centrifugation in media of different densities; none was successful. In view of the size difference between spheres and filaments, separation by differential centrifugation seemed feasible. Donald \& Isaacs (1954b) obtained a slightly higher ratio of filaments to spheres in deposits following centrifugation of infected allantoic fluids (A/Persian Gulf/2/52), but the supernatant fluids still contained appreciable number of filaments. It was thought that this poor enrichment of filaments in the deposit might be due both to the small centrifugal force used and to the very low concentration of virus in solution which, being insufficient to form a stable sedimenting boundary, would allow considerable convection to take place. In the purification scheme outlined below, 20-fold higher concentrations of virus were achieved by using a red-cell eluate of the virus and this was subjected to a considerably higher centrifugal force than that used by Donald \& Isaacs (1954 $b$ ).

Infected allantoic fluid (c. 2 l.) was passed through a fine cheese cloth chilled, and an equal volume of cold saline added. Packed human red cells 
(freshly obtained) were added in the proportion of $10 \mathrm{ml}$./l. fluid with a haemagglutinin titre of 200 . The container was occasionally shaken gently during a period of $2 \mathrm{hr}$. at $4^{\circ}$ after which the agglutinated cells were recovered by brief centrifugation and washed with chilled physiological saline. The virus was eluted by suspending the cells in $60 \mathrm{ml}$. bicarbonate saline and incubating

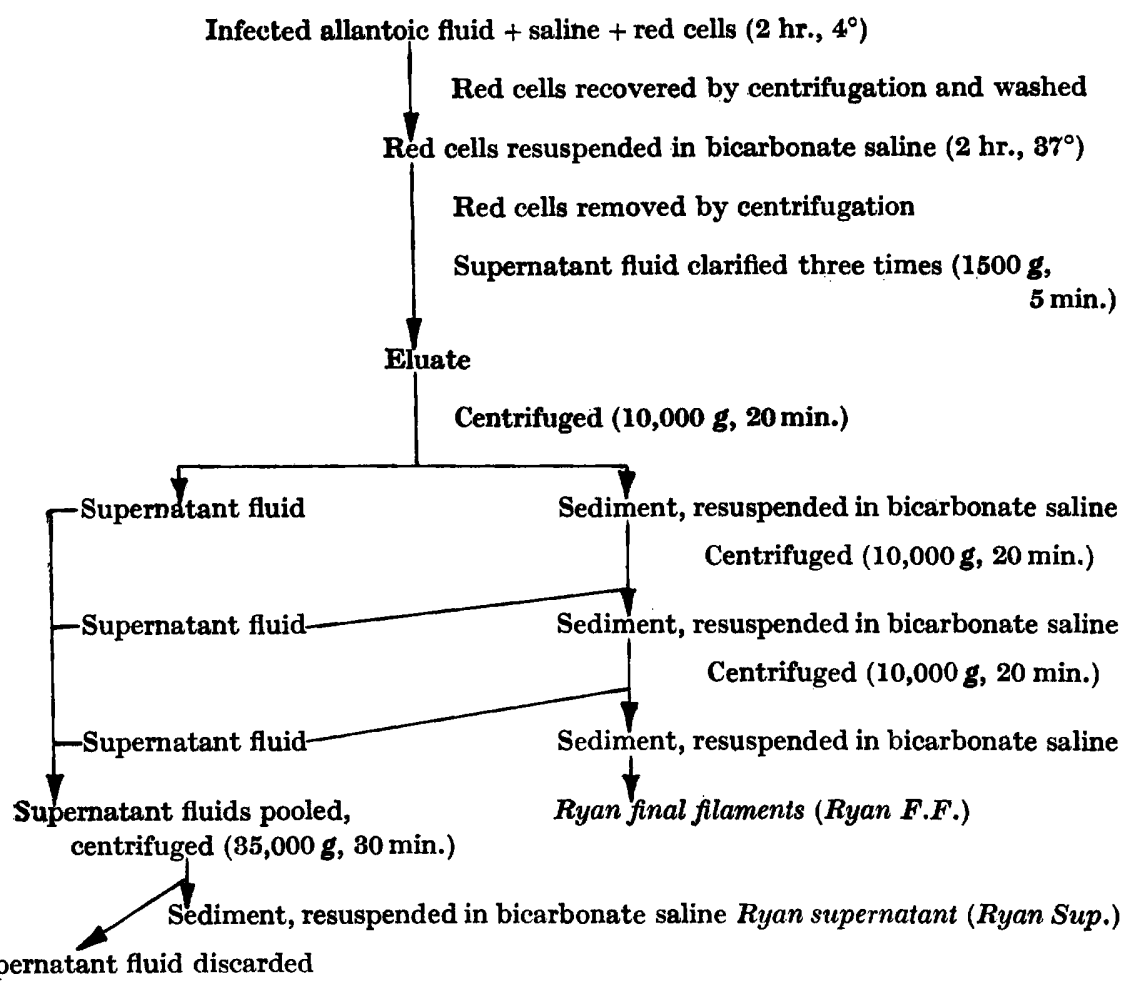

Fig. 1. Scheme for purification of filaments.

at $37^{\circ}$ for $2-2 \cdot 5 \mathrm{hr}$. The cells were sedimented in a swinging-bucket centrifuge at room temperature $(1500 \mathrm{~g}, 10 \mathrm{~min}$.). All subsequent operations were carried out at or near $4^{\circ}$. The eluate was clarified by two further centrifugations as above. The solution at this stage showed marked streaming effects when disturbed.

Samples $(20 \mathrm{ml}$.) of the supernatant fluid were centrifuged in the No. 30 rotor of the Spinco ultracentrifuge $(10,000 \mathrm{~g}, 20 \mathrm{~min}$.), the brake being left off to allow slow deceleration. The supernatant fluid was placed on one side, the residue resuspended in bicarbonate saline by gentle pipetting and the volume adjusted to $20 \mathrm{ml}$. This centrifugal cycle was repeated twice more, the final sediments being resuspended in 5-10 ml. bicarbonate saline; this solution is referred to as Ryan final filaments (Ryan F.F.). The supernatant fluids from the three sedimentations were pooled and centrifuged $(35,000 \mathrm{~g}, 30 \mathrm{~min}$.). The sediment was suspended in 5-10 ml. bicarbonate saline; this solution is referred to as Ryan supernatant (Ryan Sup.). To facilitate later reference, a flow sheet of the process is given in Fig. 1. 
Yield of purified virus (recovery of haemagglutinin). Purified Ryan Sph. virus was obtained in yields of approximately $40 \%$ (see Table 5). This is comparable with results obtained earlier (Ada \& Perry, 1956) with other strains of influenza $A$ virus, the main loss being due to incomplete resuspension of virus at the clarification stages.

Table 5. Haemagglutinin titres of infected allantoic fluids and yields of purified Ryan virus

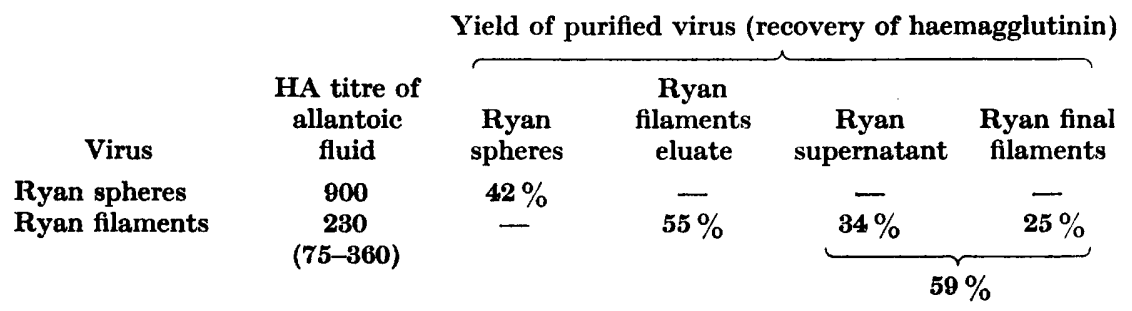

The yields of Ryan Sup. and Ryan F.F. are shown in the same table. The loss appears to occur entirely at the eluate stage. The 'recovery' of haemagglutinin from this stage may be higher than the figure in Table 5 suggests, since electron micrographs indicate that resuspension of sedimented filaments to a 'single particle suspension' is rarely achieved.

Examination of purified virus in the electron microscope. Plate 1, fig. 3, is an electron micrograph of a purified preparation of Ryan Sph. virus. The proportion of short filaments to spheres is very low. Plate 1, fig. 4, shows a preparation of Ryan Sup. There is a very small proportion of long filaments but a relatively high proportion of short filaments (about $20 \%$; see text, Fig. 2.) A preparation of Ryan F.F. is shown in Pl. 1, fig. 5. Here the proportion of filaments to spheres is approximately $1: 1$. In general, the length of the long filaments is reduced, presumably due to breakdown during purification. The ratio of long to short filaments is about $2: 1$ (Fig. 2).

Table 6. The number of virus particles per agglutinating dose of purified preparations of Ryan virus

\begin{tabular}{|c|c|c|c|c|}
\hline Virus preparations & $\begin{array}{c}\text { Mean value } \\
\text { and s.v. } \\
\left(\times 10^{-6}\right)\end{array}$ & $\begin{array}{c}\text { No. of } \\
\text { experiments }\end{array}$ & $\begin{array}{c}\text { Range } \\
\left(\times 10^{-6}\right)\end{array}$ & $\begin{array}{c}\% \\
\text { filaments }\end{array}$ \\
\hline Ryan F.F. & $10 \pm 2$ & $\mathbf{5}$ & $(7-14)$ & 48 \\
\hline Ryan F.F. supernatant & $33 \pm 5$ & 6 & $(25-38)$ & $\mathbf{2}^{*}$ \\
\hline
\end{tabular}

* Almost entirely short filaments (see text).

Number of particles/agglutinating dose of purified virus preparations. Counts were carried out on preparations of Ryan F.F. and on preparations of the supernatant fluid derived from Ryan F.F. by centrifugation at $10,000 \mathrm{~g}$ for 20 min.; the results are given in Table 6. Calculations from this figure indicate that the filaments present in Ryan F.F. are 5-6 times more efficient as haemagglutinin than are the spheres present in such preparations; this result is used in later calculations of the average weight of filaments in Ryan F.F. Though 
this value refers to a mixture of long and short filaments, the former predominate in number so that it seems likely that this decrease in efficiency as haemagglutinin is due to a partial breakdown of the long filaments.

Breakdown of filaments during purification. As already seen the proportion of short filaments to spheres in Ryan Sup. (fractionation procedure) is greater than the proportion in Ryan F. fluids (Fig. 2); this can only arise by breakdown of filaments. It is also likely that some of the spherical particles in

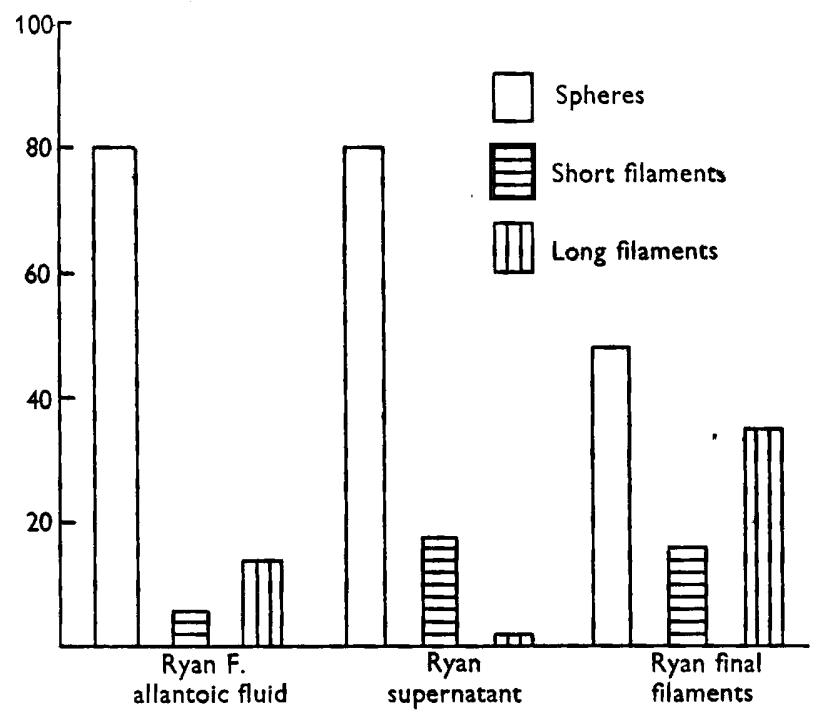

Fig. 2. Proportion of spheres, short and long filaments per 100 virus particles in crude (allantoic fluid) and purified preparations of filamentary Ryan virus.

Ryan Sup. may also have been derived from filaments. The following experiments were carried out in an attempt to see whether such a process could occur to an appreciable extent during the latter stages of purification. Essentially, the experiments tested the efficiency of the centrifugation procedure in separating spherical particles from filaments. (1) An allantoic fluid preparation of Ryan Sph. virus was purified by the method described for Ryan F. virus. The distribution of haemagglutinin in the two fractions corresponding to Ryan F.F. and Ryan Sup. was 9 and $91 \%$ respectively. (2) An eluate of Ryan F. virus was divided into two portions, each with $19 \cdot 2 \times 10^{4}$ A.D. contained in $40 \mathrm{ml}$. To one was added $10 \times 10^{4} \mathrm{~A}$.D. of purified Lee virus contained in $0.25 \mathrm{ml}$. Both solutions were then subjected to the standard differential centrifugation procedure, the haemagglutinin titre of each fraction being determined in the presence and in the absence of a potent anti-Ryan serum. At a dilution of 1:2000 this serum decreased the haemagglutinin titres of Ryan virus by approximately 100 -fold and Lee virus by two-fold (see under Methods). The haemagglutinin titres of the Ryan filaments in the presence of antiserum acted as controls to those given similarly by the Ryan and Lee mixtures, thus allowing the amount of Lee virus in the different fractions to be 
calculated. Over $90 \%$ of the Lee virus was recovered in the final fractions and showed the following distribution : Ryan Sup., $80 \%$ Ryan F.F., 20\%. This figure of $20 \%$ represents an upper limit due to the high sedimentation content of influenza B strains compared with that of A strains. It is clear then that between 10 and $20 \%$ or an average of $15 \%$ of the spheres present in the eluate may be recovered in the Ryan F.F. fraction. It is difficult to determine accurately what actual proportion of the spheres present in the Ryan F.F. fraction this would respresent but it is obviously a substantial portion. It is unlikely then that an extensive breakdown of filaments into spherical particles occurs during the centrifugation procedure.

Infectivity of purified virus preparations. In several experiments, the EID 50:AD ratios of Ryan F. and the corresponding Ryan F.F. preparations were determined. The values of this ratio for two preparations of Ryan Sph. virus were also determined. The results are given in Table 7 . The results of the

Table 7. Comparison of the values of the $\log E I D 50: A D$ ratios of crude and purified preparations of Ryan virus

\begin{tabular}{|c|c|c|c|}
\hline \multicolumn{4}{|c|}{ Virus preparation } \\
\hline \multicolumn{2}{|c|}{ Ryan filaments } & \multicolumn{2}{|c|}{ Ryan spheres } \\
\hline $\begin{array}{l}\text { Allantoic } \\
\text { fluid }\end{array}$ & $\begin{array}{c}\text { Ryan final } \\
\text { filaments }\end{array}$ & $\begin{array}{l}\text { Allantoic } \\
\text { fluid }\end{array}$ & $\begin{array}{c}\text { Purified } \\
\text { virus }\end{array}$ \\
\hline $6 \cdot 1$ & $5 \cdot 8$ & $6 \cdot 2$ & $5 \cdot 9$ \\
\hline $6 \cdot 1$ & $5 \cdot 9$ & $5 \cdot 9$ & $5 \cdot 9$ \\
\hline $5 \cdot 4$ & $5 \cdot 4$ & - & - \\
\hline $5 \cdot 6$ & $4 \cdot 9$ & - & - \\
\hline $5 \cdot 5$ & $\mathbf{5} \cdot \mathbf{3}$ & - & - \\
\hline $4 \cdot 9$ & $\mathbf{5} \cdot \mathbf{3}$ & $\longrightarrow$ & - \\
\hline $6 \cdot 2$ & $5 \cdot 1$ & - & - \\
\hline Mean values $\mathbf{5} \cdot \boldsymbol{7}$ & $5 \cdot 4$ & 6.05 & $5 \cdot 9$ \\
\hline
\end{tabular}

Ryan Sph. determinations suggest that a small loss of infectivity occurs during purification. Similar values have been previously obtained with PR8 virus (Ada \& Perry, unpublished). In the case of Ryan F. and Ryan F.F., the mean difference is slightly greater, suggesting that filaments in Ryan F.F. may be less infective than those in Ryan F. fluids. In three experiments, the (log) EID 50:AD values of preparations of Ryan F.F. and of the corresponding Ryan F.F. supernatant fluids were determined and found to be $5 \cdot 1,5 \cdot 1$; $5 \cdot 8,5 \cdot 8 ; 5 \cdot 3,6 \cdot 1$. Clearly, mean values calculated from these figures have little meaning and cannot be used with confidence to calculate the infectivity of the filaments in Ryan F.F.

Agglutinating doses/mg. dry weight of virus. The final fractions were acidified with trichloroacetic acid, the precipitate recovered by centrifugation, suspended in and dialysed against distilled water and dried in vacuo from the frozen state (Ada \& Perry, 1954). Final drying was accomplished at room temperature in a vacuum desiccator over concentrated sulphuric acid. From these weights, the values of the ratio, $A D: \mathrm{mg}$. dry weight, were calculated and are given in Table 8. The value for Ryan Sph. virus is only slightly lower than 
that found previously for other A strains. Ryan F.F. has a relatively constant but much lower value. The value for Ryan Sup. is variable and intermediate between the other two.

Table 8. Agglutinating doses/mg. dry weight of purified preparations of PR8 and Ryan viruses

\begin{tabular}{|c|c|c|c|c|}
\hline & $\begin{array}{c}\text { PR8* } \\
\left(\times 10^{-4}\right)\end{array}$ & $\begin{array}{c}\text { Ryan } \\
\text { spheres } \\
\left(\times 10^{-4}\right)\end{array}$ & $\underset{\text { supernatant }}{\stackrel{\text { Ryan }}{\left(\times 10^{-4}\right)}}$ & $\begin{array}{c}\text { Ryan final } \\
\text { filaments } \\
\left(\times 10^{-4}\right)\end{array}$ \\
\hline No. of experiments & - & 8 & 5 & 11 \\
\hline $\begin{array}{l}\text { Mean value } \\
\text { Range }\end{array}$ & $\begin{array}{l}9 \\
6-12\end{array}$ & $\begin{array}{l}6 \cdot 9 \\
5 \cdot 5-8 \cdot 1\end{array}$ & $\begin{array}{l}4 \cdot 6 \\
2 \cdot 2-7 \cdot 7\end{array}$ & $\begin{array}{l}1 \cdot 1 \\
0 \cdot 8-1 \cdot 7\end{array}$ \\
\hline
\end{tabular}

* Ada \& Perry, 1956.

Relative weights of spheres and filaments. Chemical analysis yields results which are often expressed in terms of weight or referred to some major constituent. In the case of preparations which are heterogeneous but may be divided into classes, it is essential to be able to express the results on a molecular or particle basis. This applies to the analysis of Ryan F.F. which for this purpose is conveniently divided into spherical particles and filaments, the latter ranging in length from 2 to about 100 times the diameter of a virus sphere.

From the number of particles/AD $\left(18 \times 10^{6}\right)$ and the number of $\mathrm{AD} / \mathrm{mg}$. dry weight $\left(9 \times 10^{4}\right)$, the average weight of one PR8 sphere is calculated to be about $6 \times 10^{-10} \mu \mathrm{g}$. This compares with a figure of $5 \times 10^{-10} \mu \mathrm{g}$. for the particle weight of PR 8 virus, calculated from the light absorption data of Oster (1946). Similarly, the average weight of a sphere in Ryan Sph. is $9.5 \times 10^{-10} \mu \mathrm{g}$. while that for a particle in Ryan Sup. is $5 \cdot 8 \times 10^{-10} \mu \mathrm{g}$. As Ryan Sup. contains $20 \%$ short filaments, the average weight of a sphere in Ryan Sup. would be less than $5 \cdot 8 \times 10^{-10} \mu \mathrm{g}$. From Table 8, the number of $\mathrm{AD} / \mathrm{mg}$. dry weight of Ryan F.F. is $1.1 \times 10^{4}$. As this preparation is about $50 \%$ spheres and as these filaments are about 5 times more efficient as haemagglutinin than are the spherical particles in Ryan Sup., the contribution made by spheres to $1 \mathrm{AD}$ will be $\frac{1}{8}\left(1 \times 1.1 \times 10^{4}\right)=0.18 \times 10^{4} \mathrm{AD}$. This corresponds to

$$
0.18 \times 10^{4} \times 32 \times 10^{6} \times 5.8 \times 10^{-10}
$$

or about $34 \mu \mathrm{g}$. Therefore, $966 \mu \mathrm{g}$. is due to $0.92 \times 10^{4} \mathrm{AD}$ filaments. Knowing that about 6 filaments in Ryan F.F. are equivalent to $1 \mathrm{AD}$ it can be readily calculated that one filament weighs about $180 \times 10^{-10} \mu \mathrm{g}$. or about $180: 5 \cdot 8=30$ times as much as one sphere (as in Ryan Sup.). Thus, filaments in Ryan F.F. account for over $95 \%$ of the total weight present.

\section{DISCUSSION}

Many of the points of interest arising from this investigation are best considered with the results of the nucleic acid estimations presented in the following paper. There are several points, however, which may be conveniently discussed here. It was earlier estimated that between 2 and 3 Ryan filaments 
were necessary to induce infection in the embryonated egg. This was based upon a mean value of 6.0 for the $(\log ) \mathrm{EID} \mathrm{50:AD}$ ratios given by 19 preparations of 72-hr. Ryan F. virus and on the calculation from the figures of Donald \& Isaacs $(1954 b)$ that each filament was eight times more efficient as haemagglutinin than was a spherical particle in a non-filamentous strain, PR 8 (Ada et al. 1957). In the present study, Ryan long filaments were found to be about six times more efficient as haemagglutinin than were PR 8 spheres. Furthermore, nine subsequent determinations of the (log) EID 50:AD ratio of Ryan F. preparations gave a mean value of $5 \cdot 79$. The difference in the mean values of the (log) EID 50:AD ratios for Ryan F. and Ryan F. supernatant was counterbalanced by the fact that the spheres, of which the latter fraction was largely composed, were less efficient as haemagglutinin than were PR8 spheres. Using these figures in the calculation, an estimate of six Ryan filaments: EID50 was obtained. Clearly it is not possible to settle on a definite figure but it can be confidently stated that the probability of infection in the embryonated egg by a Ryan filament is considerably greater than is the case with spherical particles present in either Ryan Sph. or PR 8 preparations. The general observation (Bang \& Isaacs, 1957; Valentine \& Isaacs, 1957; Burnet \& Lind, 1957) that filaments readily break down would of course tend to reduce this estimate of 6 particles/EID 50. This finding, together with the previous observation of Donald \& Isaacs (1954b) that 10 Persia filaments were equivalent to 1 EID 50, tends to make untenable the suggestion of Morgan et al. (1956) that filaments are a non-infectious form of virus. This point will be discussed further in the following paper.

An unexpected difference between preparations of Ryan F. and Persia F. viruses is the finding that, in contrast to the spherical particles present in Persia F. fluids, those present in Ryan F. preparations (both 21- and 72-hr. fluids) were significantly less efficient as haemagglutinin than PR 8 spheres. In 21-hr. fluids where there was a very low proportion of long filaments, about 9 spherical particles were equivalent to 1 EID 50. Thus the low efficiency as haemagglutinin does not seem to influence the infectivity of these particles. At $72 \mathrm{hr}$. this figure had decreased fourfold (see p. 29). At first sight, this could be attributed to two causes. The average haemagglutinin titre of 72-hr. Ryan F. fluids was 230 (Table 5). In such fluids, $15 \%$ of the particles are long filaments which are about 12 times more efficient as haemagglutinin than are Ryan F. spheres. Thus the spheres in these preparations contribute a haemagglutinin titre of about 75. The average haemagglutinin titre of $21 \mathrm{hr}$. fluids was 25 so that the number of spheres present at $21 \mathrm{hr}$. is increased threefold by $72 \mathrm{hr}$. If it be postulated that the later-formed particles are noninfectious, the drop in infectivity of the spheres from 21 to $72 \mathrm{hr}$. would be threefold. A complete change in infectivity of spherical particles produced before and after $21 \mathrm{hr}$. seems very unlikely. The alternative hypothesisdeterioration in chemical or physical properties-is probably largely if not completely responsible for the decrease in infectivity. The spherical particles in Ryan F. fluids may be especially susceptible to such deterioration but there is no evidence that this is the case. 
One point necessitating comment is the wide range of values for the (log) EID 50:AD ratio given by 72-hr. Ryan F. preparations. The figures vary from 6.9 to 4.9 and apply both to the spherical and filamentous particles (see tables 3 and 4). Deterioration in the value of this ratio is often regarded as evidence of 'thermal denaturation' (Horsfall, 1954). Despite the fact that the bulk of the particles present in Ryan F. are produced during the first $30 \mathrm{hr}$. incubation and are then subjected to a further $30 \mathrm{hr}$. at $35^{\circ}, 10$ of the 29 values quoted for the (log) EID 59:AD ratios were 6.2 or greater. Clearly other factors as well as temperature of incubation affect the infectivity of the virus. This wide range of values is not mainly due to variation in eggs, inconsistency of technique, etc., as 21-hr. Ryan F. fluids which were titrated at the same time as 72-hr. Ryan F. fluids, consistently had high values for the (log) EID 50:AD ratio ('Table 3). Obviously there has been little chance of particle deterioration in 21-hr. fluids. Thus if preparations of Ryan F. containing mainly 'undamaged' particles have values for the (log) EID 50:AD ratio of 6.2 or greater, the estimate of 6 long filaments/EID 50 would be greatly reduced.

These results further emphasise that quoting values for the ratio (log) EID 50:AD is an incomplete description of the infectivity of a virus preparation. Particle counts are necessary to complete the picture. It has been generally considered that the average value for the (log) EID 50:AD ratio of standard virus preparations is about 6.2 (see review by Isaacs, 1957). Values consistently higher than this have been occasionally obtained, e.g. with Rob virus, a B strain of recent human origin (Ledinko \& Perry, 1955). The explanation for such findings may also be the presence of spherical virus particles of low efficiency as haemagglutinin.

We wish to thank Drs H. B. Donald and J. M. Edney who were concerned in the initial stages of the investigation, and Professor Sir Macfarlane Burnet, F.R.S., for his advice and encouragement. This work was aided by a grant from the National Health and Medical Research Council, Canberra, A.C.T., Australia.

\section{REFERENCES}

Ada, G. L. \& Perry, B. T. (1954). The nucleic acid content of influenza virus. Aust. J. exp. Biol. med. Sci. 32, 453.

AdA, G. L. \& Perry, B. T. (1956). Influenza virus nucleic acid: relationship between biological characteristics of the virus particle and properties of the nucleic acid. J. gen. Microbiol. 14, 623.

ADA, G. L., PERRy, B. T. \& EDNEY, M. (1957). Infectivity of influenza virus filaments. Nature, Lond. 180, 1134.

BANG, F. B. \& IsAacs, A. (1957). Morphological aspects of virus cell relationship in influenza, mumps and Newcastle (myxovirus). The Nature of Viruses, p. 249. Ciba Foundation Symposium. London: Churchill.

Burnet, F. M. \& Lind, P. E. (1957). Studies on filamentary forms of influenza virus with special reference to the use of dark-ground-microscopy. Arch. Virusforsch. 7, 413.

Burnet, F. M., McCrea, J. F. \& Stone, J. D. (1946). Modification of human red cells by virus action. 1 . The receptor gradient for virus action in human red cells. Brit. J. exp. Path. 27, 228. 

Journal of General Microbiology, Vol. 19, No. 1
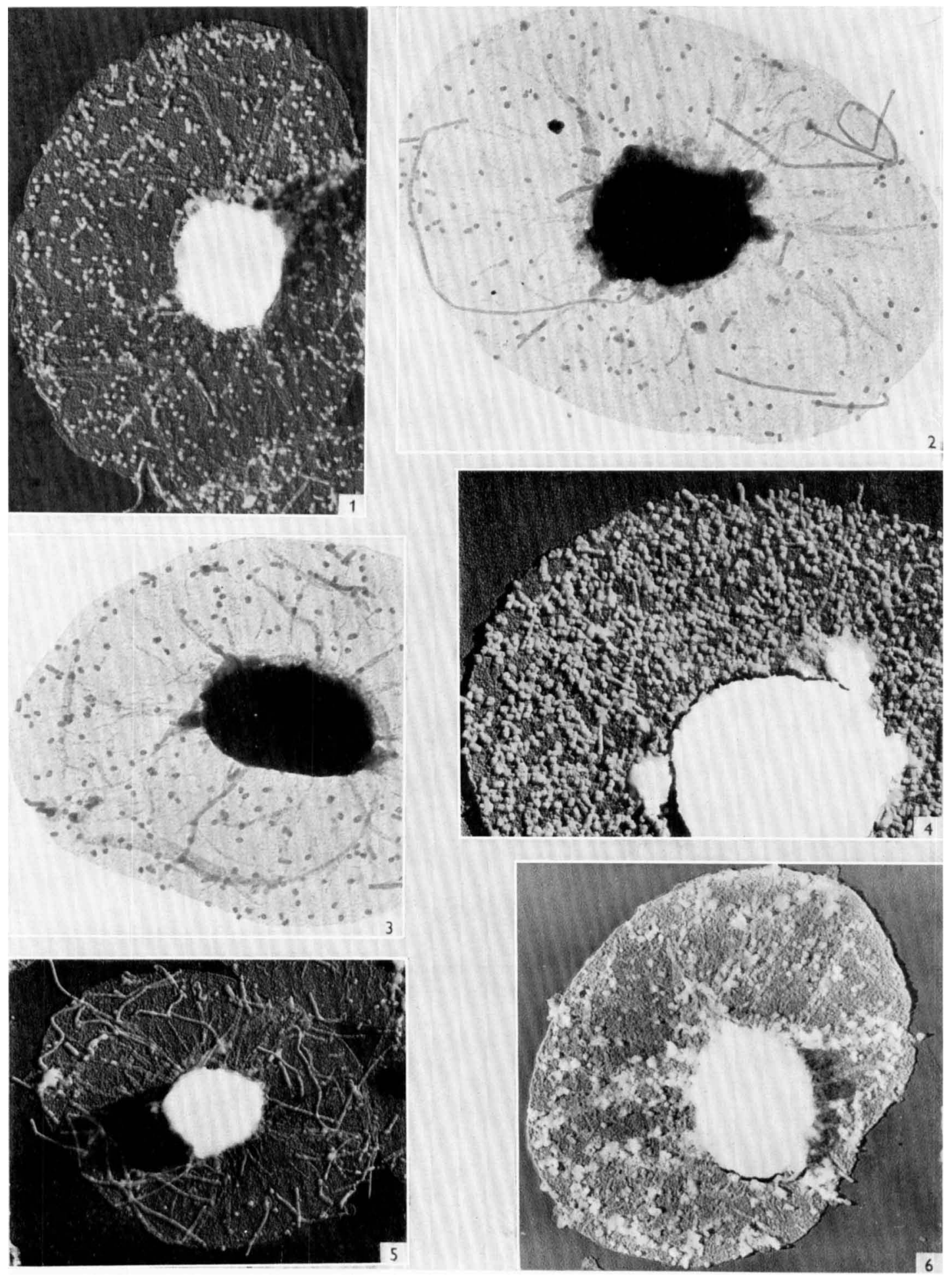

G. L. Ada, B. T. Perry and A. Abbot-Filamentous influenza virus. Plate 1

(Facing p. 39) 
Chu, C. M., Dawson, I. M. \& Elford, W. J. (1949). Filamentous forms associated with newly isolated influenza virus. Lancet. $\mathrm{i}, 602$.

Donald, H. B. \& IsaAcs, A. (1954a). Counts of influenza virus particles. J. gen. Microbiol. 10, 457.

Donald, H. B. \& IsaAcs, A. (1954b). Some properties of influenza virus filaments shown by electron microscopic particle counts. J. gen. Microbiol. 11, 325.

Fisher, R. A. (1954). Statistical Methods for Research Workers, 12th ed. London: Oliver and Boyd.

Francis, T. (1934). Transmission of influenza by filterable virus. Science, 80, 457.

Francis, T. (1940). New type of virus from epidemic influenza. Science, 92, 405.

Hrrst, G. K. (1952). Strain-specific elements in influenza antigens. J. exp. Med. 96, 589.

Horsfall, F. L. (1954). On the reproduction of influenza virus. Quantitative studies with procedures which enumerate infective and haemagglutinating virus particles. J. exp. Med. 100, 135.

IsaAcs, A. (1957). Particle counts and infectivity titrations for animal viruses. Advanc. Virus Res. 4, 111.

Ledinko, B. \& Perry, B. (1955). Studies with influenza B of recent human origin. 1. Adaption to the mouse lung. J. Immunol. 74, 371.

Morgan, C., Rose, H. M. \& Moore, D. H. (1956). Structure and development of viruses observed in the electron microscope. III. Influenza virus. J. exp. Med. 104, 171.

OsTen, G. (1946). Molecular weights and other properties of viruses as determined by light absorption. Science, 103, 306.

Tyrrell, D. A. J. \& Valentine, R. C. (1957). The assay of influenza virus particles by haemagglutination and electron microscopy. J. gen. Microbiol. 16, 668 .

VALENTINe, R. C. \& IsaAcs, A. (1957). The structure of influenza virus filaments and spheres. J. gen. Microbiol. 16, 195.

\section{EXPLANATION OF PLATE}

Electron micrographs of preparations of virus adsorbed on to laked avian erythrocytes.

Fig. 1. Ryan Spheres (72 hr.). Shadowed with gold manganin. Magnification $\times 8000$.

Fig. 2. Ryan filaments $(72 \mathrm{hr}$.). Unshadowed. Magnification, $\times \mathbf{9 0 0 0}$.

Fig. 3. Purified Ryan spheres. Unshadowed. Magnification, $\times 9000$.

Fig. 4. Ryan supernatant. Shadowed with gold manganin. Magnification, $\times 12,500$.

Fig. 5. Ryan final filaments. Shadowed with gold manganin. Magnification, $\times 6000$.

Fig. 6. Ryan final filaments after 10 cycles of freezing and thawing (see following paper). Shadowed with gold manganin. Magnification, $\times \mathbf{7 0 0 0}$. 